\title{
Berkeley no país das Luzes: ceticismo e solipsismo no século XVIII
}

\author{
Sébastian C harles \\ Université de Sherbrooke
}

resumo A influência do ceticismo nos século XVI e XVII é por demais evidente para ser posta em questão. De Montaigne a Bayle, parece que o cético foi o promotor tanto de uma refutação radical dos princípios metafísicos escolásticos e depois cartesianos quanto de uma crítica feroz às autoridades religiosas e políticas. Ora, esse papel parece ter se amenizado no Século das Luzes, ou melhor, se deslocado - somente as dimensões críticas do social continuaram pertinentes. Pretende-se mostrar aqui o pressuposto de uma tal leitura que leva em conta apenas 0 aspecto visível da crítica cética e mostrar que 0 ceticismo, sob uma forma particular (o solipsismo), foi uma das grandes questões da epistemologia das Luzes e que ele é indissociável, para ser compreendido em toda a sua dimensão polêmica, da recepção européia do imaterialismo berkeleyano. 0 objetivo de nossa intervenção se faz compreender então claramente: explicar primeiramente como uma tal concepção epistemológica pôde nascer em terra cartesiana e quais foram os seus líderes desse solipsismo das Luzes, a supor que os tenha havido, para mostrar, em seguida, porque ela pôde se tornar uma questão metafísica maior no século XVIII, antes de definir, para concluir, os interesses a que ela serviu ou desserviu.

palavras-chave cartesianismo - imaterialismo - Luzes - materialismo - metafísica ceticismo - solipsismo.

Se eu começasse por Ihes confessar pura e simplesmente que duvido firmemente da existência de um público nesta sala, ou mesmo da existência da própria sala, e que São Paulo é apenas o produto de minha consciência, como aliás, de modo mais geral, o mundo inteiro, vocês

R ecebido em dezembro de 2004. A ceito em janeiro de 2005.

doispontos, Curitiba, vol. 1, n. 2, p.11-33, jan/ jun, 2005 
duvidariam, creio que com razão, de meu estado mental, e recomendarme-iam uma estada naquilo que, no século XVIII, era chamado de "petitesmaisons" e que hoje batizamos mais comumente de asilo psiquiátrico.

$\mathrm{N}$ o entanto, por estranho que possa parecer, a teoria que postula que uma única consciência poderia ser a fonte única de toda existência mundana parece ter tido diversos discípulos no Século das Luzes, o que pode parecer em si mesmo paradoxal, uma vez que essa doutrina afirma exclusivamente a existência de um único ser. Eu gostaria, aqui, apenas de explicar rapidamente como uma tal concepção, que foi qualificada de egoísmo ou de egomet (o egoísta sendo o indivíduo que se acredita o único existente), pôde nascer em terra cartesiana, quais foram seus líderes (a supor que os tenha havido), por que razão ela pôde tornar-se uma questão metafísica maior no século XVIII e quais são os interesses que ela serviu ou desserviu.

\section{As conclusões solipsistas da refutação cartesiana do ceticismo}

De saída, poder-se-ia pensar que a doutrina egoísta tem uma relação intrínseca com o ceticismo antigo. $\mathrm{N}$ ada disso. Por certo, C ícero real mente nos diz que $M$ etrodoro de $Q$ uios não conseguia decidir-se acerca da existência das coisas² e Sexto Empírico (s/ d, I, 65-87) atribui, de seu lado, essa afirmação a Górgias, ao passo que Sêneca a põe na boca de Z enão de Eléiz3. M as, de um modo geral, tais afirmações são excepcionais e não têm maior peso. 0 que interessava os céticos da antigüidade era antes de tudo o estatuto que se deve conceder à ordem fenomenal, às aparências; era criticar 0 saber sensível ao invés de dizer que os sentidos não percebiam nada. Montaigne, no R enascimento, ecoará um tal ceticismo: "[0 homem] não pode esquivar- se ao fato de que os sentidos sejam os mestres soberanos do conhecimento; mas eles são incertos e falsificáveis em todas as circunstâncias" (MONTAIGNE, 1962, p. 576). Enfim, antes de Descartes, a questão da existência do mundo exterior não se põe, pelo menos não com a radicalidade que o cartesianismo conferir-lhe-á.

Com efeito, foi Descartes quem pôs o problema da existência do mundo exterior, ao procurar subverter a ordem das certezas e fazer da 
existência da alma, pelo viés da descoberta do cogito, uma certeza mais imediata que a do corpo.Tal não era, é claro, sua intenção primeira, uma vez que D escartes toma por tão certa a existência do corpo quanto a da alma, a do cogito sendo simplesmente metodologicamente primeira na ordem dos conhecimentos. Pois, para ele, a existência necessária de um D eus bom garante de maneira definitiva que as sensações que percebemos remetem efetivamente a algo existente fora de nós, mesmo se elas não nos permitem conhecer sua natureza ${ }^{4}$ - a extensão, a título de substância, só podendo ser compreendida pelo entendimento.

M esmo na época de Descartes, essa solução para o problema da existência dos corpos exteriores, por engenhosa que fosse, não resolvia em nada a questão. $R$ egius, por exemplo, considerava que $D$ eus podia ter boas razões para enganar-nos (para nosso bem ou ainda para punir-nos por nossos pecados). E mesmo se ele não era enganador, podia facilmente nos afetar do mesmo modo, com ou sem matéria. Enfim, para R egius e Géraud de Cordemoy, muito embora discípulo de D escartes, não deixa por menos -, sem a fé que evoca a criação do universo, a existência do mundo exterior permanece problemática.

É essa solução que M alebranche retoma, fazendo exclusivamente da fé a garantia da objetividade do mundo. Tal solução decorre de seu sistema, no qual só Deus é causa eficaz, os corpos não podendo agir sobre o espírito. D esde então, sem a fé, nenhuma certeza metafísica é possível: "é por um ato livre e, em conseqüência, sujeito a erro que assentimose não por uma impressão invencível: pois acreditamos por assim o querermos livremente e não porque 0 vejamos com uma evidência que nos põe na necessidade de acreditar [na existência do mundo] como o fazem as demonstrações matemáticas" (M ALEBR ANCHE, 1958-1967, "VIo esclarecimento", p. 64). 0 ra, a liberdade supõe a possibilidade do erro e, ali onde não temos demonstração certa, devemos remeter-nos à fé, tese que A rnauld criticará no capítulo 28 das $V$ raies et fausses idées.

A despeito dessa crítica, é a posição de $M$ alebranche que prevalecerá. 0 abade de Lanion, em suas M éditations sur la métaphysique, que publicou em 1678 em Paris sob o pseudônimo de Guillaume Wander, irá mesmo levar até 0 fim 0 malebranchismo e, mais particularmente, a tese da simplicidade das vias: "D eus, que age sempre pelas vias mais simples, sendo a causa imediata de minhas modificações, tenho razões para pensar 
que seria um desvio excessivamente longo para esse ser infinitamente sábio isso de criar a extensão para dar-me sensações que ela não pode produzir" (Lanion apud PILLON, 1895, p. 126)5. 0 raciocínio é bem montado. C om efeito, de que serve a criação da matéria se D eus é capaz, sem ela, de produzir em nós modificações exatamente similares àquelas que teríamos se ela existisse? R esta que Lanion concede, ele também, que a fé garante a existência dos corpos exteriores, mas acrescenta que um tal ato de fé vai de encontro às deduções da razão e faz dessa existência um puro mistério. É também a opinião de um professor de filosofia paduano, $M$ ichelangelo Fardella, que chega mesmo a mostrar que a fé talvez não seja um critério de certeza exemplar, pois a Sagrada Escritura possui diferentes sentidos e seria bem possível que os trechos nos quais ela menciona a existência dos corpos sejam destinados apenas aos iletrados e não aos filósofos. Essa idéia é compartilhada, desta vez na Inglaterra, por John N orris, que também se recusa a ver no texto revelado uma prova demonstrativa dessa existência dos corpos, uma vez que todo texto é, em si mesmo, um pedaço de matéria.

Do lado dos adversários do cartesianismo, os impasses aos quais a filosofia moderna conduz foram igualmente notados. U m cético como $\mathrm{H}$ uet delicia-se aqui, ainda que ele próprio seja obrigado a recorrer à fé para decidir a questão da existência dos corpos exteriores. ${ }^{6}$. Por outro lado, Simon Foucher, próximo do ceticismo acadêmico, retoma a grande distinção cartesiana entre qualidades secundárias e primárias a fim de provar a impossibilidade, para os defensores de uma tal diferenciação, de conseguir resolver o problema do solipsismo. Pois, se os cartesianos reconhecem que a percepção das qualidades secundárias remete ao sujeito, deveriam igualmente aceitar reconhecer que as qualidades primárias são tão perfeitamente subjetivas quanto aquelas.

Essa intuição, como se sabe, foi retomada por Bayle no famoso artigo "Pirro" de seu D icionnaire historique et critique e, acrescentada a um argumento deveras interessante, conduz a derrubar a tese cartesiana da veracidade divina. Com efeito, se os homens pensaram desde o começo da humanidade que as qualidades ditas secundárias eram inerentes aos objetos sem que isso seja compreendido como uma enganação divina, por que seria diferente hoje com as qualidades primárias? 0 u, para dizê-lo com as palavras de Bayle: "D esde o começo do mundo, todos os homens, com a 
exceção talvez de um em duzentos milhões, acreditam firmemente que os corpos são coloridos e isso é um erro. Eu pergunto: Deus engana os homens com relação a essas cores? Se ele os engana a esse respeito, nada impede que ele os engane a respeito da exten são" (BAY LE, 1820a, p. 102, obs. B). A esse argumento inescapável Bayle acrescenta, dessa vez no artigo "Zenão", a tese da simplicidade das vias, tomada de Lanion. M as a fé não poderia garantir a existência do mundo exterior? N ão, pois como bom leitor de Fardella, Bayle sabe que toda fundamentação da certeza da existência da extensão sobre a fé deve ser tida por nula e inexistente. A lém disso, ele nota a justo título a circularidade do argumento: "supondo que Jesus C risto tenha-se acomodado à lógica popular, não se pode provar pela Escritura que há corpos: como então estar-se-ia assegurado pela fé de que há corpos" (BAY LE, 1820b, p. 50, obs. H), uma vez que essa última repousa sobre o texto sagrado, corpóreo de uma ponta à outra?

Enfim, no momento em que termina um século e começa um outro, o solipsismo parece surgir como uma posição filosófica coerente, para não dizer legítima. Podemos encontrar seus vestígios em um manuscrito clandestino do início do século XVIII - as R éflexions morales et métaphysiques sur les religions et les connaissances de l' homme (cf. CH AR LES, 2000a) - e nas revistas científicas da época que disseminam o debate7. A ssim são publicadas, no M émoires de Trévoux de 1704-1705, duas violentas diatribes contra o cartesianismo, que fazem dele uma porta de entrada indiscutível para o solipsismo e uma causa possível dos sucessos do ateísmo (posto que o solipsismo arruína a prova cosmológica da existência de D eus), acusando-o de tornar as disputas metafísicas modernas estéreis e de afastar assim os livres pensadores da simplicidade da religião cristã.

A ssim, o cartesianismo, que pretendia ser a panacéia ideal que corta na raiz as especulações céticas, não fez mais, até mesmo segundo seus defensores, do que reforçar a mais radical de todas as dúvidas, aquela que versa sobre a existência de toda e qualquer coisa, e não produziu, para seus detratores, nenhuma prova demonstrativa permitindo resolver os problemas que criou. Compreende- se então o juízo sem meias-tintas de um gassendista como François Bernier no final do século XVII: "N ão sei se devo dizer-vos que os cartesianos, à força de especular sobre seu grande princípio: penso, logo existo, acabaram não apenas por acreditar que é bem mais fácil demonstrar que há substâncias espirituais do que 
corporais, mas por duvidar de que haja algum corpo na natureza e mesmo a tomar por provável que não haja nenhum e que tudo seja espírito" (BER N IER , 1835, p. 373).

\section{0 egoísmo: realidade parisiense ou invenção necessária?}

Se os filósofos da segunda metade do século XVII tiveram que se haver com a questão do solipsismo, ninguém no entanto desejou endossar uma tal posição. 0 ra, no início do século X VIII, parece que a cena intelectual parisiense tenha sido invadida pelos egoístas. As pessoas não cessam de mencionar sua existência, de combatê-los de modo feroz, de zombar deles, mas eles nunca são citados nominalmente, com a exceção de Berkeley. Berkeley egoísta? Parece difícil de acreditar, quando se sabe, de um lado, que sua obra se apresenta como uma refutação do ceticismo e do ateísmo e, de outro, que a existência dos corpos exteriores, no imaterialismo, não se constitui em um problema. No entanto, salvo raras exceções, seu pensamento será confundido com o dos egoístas, pela única razão de que os jesuítas terão assim decidido, e isso a fim de melhor refutar $M$ alebranche (excessivamente próximo do necessitarismo espinosista, segundo eles), atribuindo-Ihe discípulos com doutrinas disparatadas, tais como o solipsismo.

Pois se 0 egoísmo conquista cidadania no pensamento filosófico francês do início do século XVIII, é antes de tudo sob as feições de Berkeley; uma tal identificação é obra dos jesuítas. Primeiro, graças a duas recensões parciais dos primeiros textos de Berkeley (o Tratado dos prinápios do conhedimento humano e os $\mathrm{D}$ iálogos entre $\mathrm{H}$ ilas e $\mathrm{F}$ ilonous), publicadas em 1713, que apresentam Berkeley como "um malebranchista de boa fé" que "levou sem meias-medidas os princípios de sua seita bem além do senso comum e [que] disso concluiu que não há nem corpo nem matéria e que apenas os espíritos existem" (M ÉM O IR ES DE TR ÉVO U X , 1713, p. 921). D epois, devido a uma aproximação duvidosa, o autor anônimo do M émoires deT révoux, alegando conhecer um "malebranchista que vai mais longe do que o sr. Berkeley" e crê ser "o único ser criado que exista" (ibidem) ${ }^{8}$. Aqui, novamente, nenhuma precisão é-nos fornecida acerca da identidade desse egoísta. 
Cinco anos depois, quando as $\mathbb{E}$ uvres philosophiques de Fénelon, dirigidas por R amsay, são publicadas por Estienne, Tournemine, então diretor do M émoires de Trévoux, acrescenta as R éflexions sur l'athéisme, já publicadas em 1713, mas dessa vez aumentadas por três páginas contra os espinosistas e seis contra Berkeley, retomadas, alguns meses depois, no M émoires deT révoux, de janeiro de 1719. Por que toda essa sanha? Simplesmente porque 0 imaterialismo parece então substituir-se ao espinosismo e seduzir a intelligentsia. 0 líder dessa seita de imaterialistas, Berkeley, toma o contrapé exato do espinosismo, pelo menos daquele que Tournemine inventou de uma ponta à outra, afirmando que tudo é espírito ali onde Espinosa dizia que tudo é matéria. D esde então, o mundo material não é senão uma fantasmagoria que só existe no espírito daquele que o pensa e que se apresenta a ele segundo uma necessidade inteiramente natural ${ }^{9}$. Esse naturalismo é, paraTournemine, indicativo de um profundo imora lismo e, sobretudo, de um ateísmo radical que derruba toda prova cosmológica da existência de D eus. Felizmente, acreditaTournemine, esse sistema, por seus próprios excessos, não terá lá muitos adeptos. De um lado, porque se opõe ao senso comum; de outro, porque a presença em nós de idéias que não remetem a nós mesmos implica a existência de um D eus todo-poderoso e, por fim, porque todo imaterialista conseqüente deve ou bem reconhecer que seu espírito foi criado (o que supõe remontar a uma causa primeira, coisa que os egoístas, descritos como ateus, deveriam recusar) ou que ele é eterno - mas, nesse caso, haveria um momento em que ele não pensaria e só seria ativo de um certo tempo para cá, o que implicaria fazer intervir a temporalidade no seio mesmo da eternidade, o que é absurdo. Enfim, Tournemine conclui mostrando que se trata aí de "suposições bizarras para as quais não se vê nenhum funda mento; na verdade, os incrédulos querem fazer-nos acreditar em coisas mais incríveis do que todos os mistérios" (FÉN ELO N, 1718, p. 368).

Tournemine não leu uma linha sequer das obras de Berkeley, isso parece evidente. $\mathrm{N}$ ão obstante, sua opinião terá uma repercussão certa, as $\mathbb{F}$ uvres philosophiques de Fénelon sendo largamente difundidas e reeditadas onze vezes entre 1712 e 1740. L'E urope savante, dando uma recensão da obra em abril de 1719, ecoará as observações de Tournemine. Berkeley é ali descrito como o autor do sistema dos imaterialistas, doutrina que prega que "tudo é espírito; o mundo não é mais que um 
composto de seres pensantes; tudo o que de corpóreo cremos ver, sentir, não é mais que um fantasma que nosso espírito fabrica para si, ou antes, que nasce em nós pela necessidade natural que nos fez nascer" (L'EU R O PE SAVAN TE, 1719, art. I, p. 189). 0 egoísmo é doravante um fato social, uma doutrina sem dúvida estranha, mas que no entanto merece ser refutada.

U ma vez que foram os jesuítas que criaram, de ponta a ponta, o problema, serão portanto eles os primeiros que se encarregarão de resolvêlo. Foi sem dúvida alguma o Père Buffier quem se consagrou o mais seriamente a essa tarefa. Consciente dos riscos que o egoísmo podia fazer correr à fé cristã, ele crê necessário não apenas refutá-lo, como também propor um sistema filosófico que possa garantir a existência dos corpos exteriores. Esse sistema tem por fundamento a doutrina do senso comum, única apta a substituir o cartesianismo que, embora refute efetivamente os céticos, forçando-os a conceder a existência de uma certeza (a do cogito), não consegue libertar-se do solipsismo e, portanto, só executa metade do trabalho. 0 ra, diz-nos Buffier, com o cogito apenas, uma conseqüência desse tipo é inevitável, pois o testemunho dos sentidos é recusado (os corpos não existindo), a autoridade humana ou divina vê- se contestada (uma vez que toda autoridade age sobre nós por intermédio dos sentidos) e a ação imediata de D eus torna-se problemática (uma vez que a própria suposição de D eus implica um ser diferente daquele que se crê $o$ único existente; o que é contraditório com o sentimento íntimo que põe como única evidência a atividade da consciência do sujeito). Enfim, os partidários do sentimento íntimo podem, em toda boa fé, pôr a inexistência, fora deles, do mundo exterior.

Parece portanto que o egoísmo seja irrefutável uma vez posto o sentimento íntimo. $R$ esta o bom senso, que Buffier designa sob a expressão de senso comum, a saber, "a disposição que a natureza pôs em todos os homens ou manifestamente na maior parte dentre eles [que se note a nuança, que permite dar conta da existência dos egoístas], para fazer-Ihes emitir, quando atingem a idade da razão, um juízo comum e uniforme sobre objetos diferentes do sentimento íntimo de sua própria percepção, juízo que não é a conseqüência de nenhum princípio anterior" (BU FFIER, 1732, p. 564). Graças ao senso comum, podemos superar o solipsismo e fundar verdades primeiras 10 independentes do sentimento íntimo e, para a maioria 
dos indivíduos, dotadas de uma evidência quase tão forte quanto a deste, a mais evidente das quais põe, antes da existência de D eus"1, a "de outros seres e de outros homens além de mim". Para fechar o debate com os céticos, bastará dizer que o solipsismo não é uma verdade primeira (um sentimento natural), mas que se trata de uma proposição filosófica adquirida por um raciocínio complexo que o senso comum recusa. 0 que parece um tanto fraco, pois o senso comum é também naturalmente persuadido de que a terra gira em volta do sol e apenas um raciocínio também complexo pode retificar o que o sentimento natural persuade-nos a acreditar. A resolução do problema da existência do mundo exterior, por Buffier, reduz-se portanto a dizer que os corpos existem porque é uma primeira verdade e que é uma primeira verdade porque 0 assentimento quase universal dos homens no tempo e no espaço prova- 0 . Q uanto àqueles que, à força de reflexões, chegarem ao sentimento contrário, é muito simplesmente porque terão perdido o senso comum.

A partir dessas diversas tentativas de refutação, como não acreditar a seita egoísta realmente ativa? Compreende-se então que, desde 1719, Wolff a evoque por meio da menção à existência, em Paris, de indivíduos que "recusam a existência de todas as coisas mas admitem a do Ego (das I ch)" (W O LFF, 1719, § 2, 944; cf. também W O LFF, 1724, p. 75). M as quem são eles? Wolff, que Ihes concede um lugar enquanto variante sutil do idealismo no esquema dos sistemas de filosofia que ele traça nos parágrafos 32 a 43 do capítulo primeiro da Psychologia rationalis de 173412 , ensina-nos igualmente a existência de um egoísta, discípulo de $M$ alebranche ${ }^{13}$, que teria professado sua doutrina em Paris e que contra toda expectativa teria ali recrutado vários discípulos, sem, contudo, fornecer-nos seu nome. A lguns anos antes, Pfaff (1722) expunha a história da seita em uma dissertação intitulada 0 ratio de E goismo, nova philosophica haeresi, e nomeava, dessa vez, seus inspiradores (D escartes e, sobretudo, $M$ alebranche) e seus chefes ( Fardella e Berkeley, é claro, mas também A rthur Collier).

$\mathrm{N}$ a verdade, para ter nomes precisos, será preciso endereçar-se a obras obscuras. Assim, segundo Flachat de Saint-Sauveur (pseudônimo, segundo Barbier, de Jérôme du Perrier e de Anthelme de Tricaud), autor de P ièces fugitives d' histoire et de littérature anciennes et modernes datadas de 1704, um certo Jean B runet, médico de profissão, teria feito publicar, na esteira de leituras na casa do abade de Cordemoy, filho do célebre filósofo, um 
Projet d'une nouvelle métaphysique em 1703. D escobrimos nesse Projet uma nova filosofia que tem "por princípio fundamental que apenas ele [B runet] existe no mundo; que seu pensamento é a causa da existência de todas as criaturas; que nas ocasiões em que, para a infelicidade do gênero humano, ele cessa de pensar nelas, elas aniquilam-se" (DE SAIN T-SAU VEU R, 1704, segunda parte, $p$. 356). $M$ as nunca ninguém conseguiu encontrar o menor rastro desse escrito gabando o egoísmo e as outras obras que possuímos de Brunet permitem duvidar de seu estatuto de solipsista. R esta, não obstante, um texto espantoso, uma "Teoria particular do movimento", em que podemos ler que "cada um deve procurar em seus próprios recursos a razão e a causa das aparências do mundo imaginário em que ele preside só" (BRU N ET, 1687, p. 210). Segue-se uma tentativa de definição do espírito como lugar ao mesmo tempo da consciência e das idéias do entendimento e da imaginação, idéias que se diferenciam por sua forma e não por sua objetividade e que representam as coisas externas tais como nos aparecem, que só diferem entre si por sua situação no espaço e sua figura. Esses corpos externos são compostos de átomos, que estão em movimento ou em repouso e que ocupam todo o espaço disponível, com exceção do vazio que os separa uns dos outros. I sso é deduzido apenas pelo pensamento, que só precisa do mundo exterior como confirmação daquilo que ele deduz a priori. M as Brunet deixa-nos nesse estágio da análise, sob o pretexto de uma próxima obra em que extrairá todas as conseqüências disso e reconciliará o idealismo absoluto que ele apresenta aqui com o sensualismo defendido em 1695 em seu Projet de médeane. $\mathrm{N}$ ão se pode portanto fazer de Brunet, a partir apenas dos textos que possuímos, um solipsista.

0 utro pretenso egoísta: G aspard Langenhert. D e origem holandesal4, estabelece-se em Paris em junho de 1697, onde, segundo Lefebvre de Beauvray, autor em 1770 de um D ictionnaire sodal et patriotique, teria professado o egoísmo: "Enquanto estes [os idealistas], seguindo o exemplo de B erkeley, só percebem a existência dos espíritos, aqueles [os materialistas] só vêem a dos corpos. Alguns, que se acreditam mais razoáveis que os outros e que o são ainda menos, só admitem como realidade a de seu ser próprio e individual. Esse último sistema, sob o nome de egoísmo, foi sustentado recentemente, e mesmo em Paris, de maneira bastante pública por um sofista holandês chamado L anghner" (DE BEAU VR AY 
1770b, p. 328. 15. V isivelmente inspirada em Wolff, essa indicação teria realmente alguma legitimidade? É tão difícil sustentá- lo nesse caso quanto 0 fora no de Brunet. A qui também as referências são de segunda mão e 0 texto de Lefebvre de Beauvray data de 1770, ou seja, mais de 60 anos após os fatos que relata.

No entanto, dessa vez nós dispomos de um texto de Langenhert, o $\mathrm{N}$ ouveau philosophe. Seria ele realmente o breviário do solipsismo? $\mathrm{N}$ ão é, em todo caso, o do ceticismo, uma vez que, de saída, Langenhert anuncia, como bom discípulo de Geulincx ${ }^{16}$, que a dúvida não é nada, uma vez que não há meio-termo entre conhecer e ignorar e que a suspensão do juízo é um procedimento puramente retórico, pois conhecer e julgar são coisas idênticas. A isso se acrescentam uma refutação dos universais (Langenhert é um nominalista convicto), uma crítica da noção de causa lidade (ele afirma a identidade da causa e do efeito e quer que toda coisa só seja conhecida por si mesma) e do ocasionalismo, uma discussão cerra da da distinção entre potência e ato (que ele recusa) e, o que nos interessa mais particularmente, uma atenção detida à problemática da existência dos corpos. Ele mostra, de início, que foi D escartes quem, a esse respeito, criou um problema que não deveria ter sido posto e não soube resolvê10: "nosso filósofo nega absolutamente que D escartes tenha demonstrado a existência dos corpos fora de nosso entendimento e, além disso, sustenta que o exato oposto segue-se dos próprios princípios de D escartes ou, pelo menos, que por seus princípios não podemos ter um conhecimento certo da existência dos corpos" (LAN GEN HERT, 1701, p. 41). A seguir ele acrescenta - e seu nominalismo só poderia levá-lo a isso, como levará B erkeley à mesma conclusão alguns anos mais tarde - que a existência de uma extensão substancial é altamente problemática (idem, p. 87-91). Ele termina, por fim, com uma constatação algo ambígua acerca da existência das coisas materiais fora de nós: "Todo mundo está persuadido de que há corpos fora de nós e de que há coisas materiais que existem fora de nosso espírito; no entanto, ninguém oferece disso uma boa razão e talvez não se tenha encontrado nenhuma" (LAN GEN HERT, 1702, p. 65).

A tento aos debates internos ao cartesianismo, Langenhert lembra 0 argumento cartesiano da veracidade divina, as críticas que lhe foram feitas pelos ocasionalistas e notadamente a simplicidade das vias; ele retoma a crítica de Foucher acerca da semelhança, destrói a distinção cartesiana 
entre extensão formal e objetiva e ataca de maneira violenta 0 abuso pelos cartesianos dos termos "claro" e "distinto"; usa o argumento do sonho e mostra que os cartesianos não podem refutá-lo e, desse procedimento, conclui simplesmente que "se segue dos princípios do sr. Descartes ou que não há corpos que existam fora de nós, isto é, fora de nosso espírito, ou que não podemos saber que eles existem" (idem, p. 87).

Assim, o cartesianismo só pode levar ao ceticismo e é por isso que é preciso libertar-se dele e propor uma nova filosofia. Será ela apta a provar aquilo que D escartes não conseguiu? N osso philosophus novus tem sérias dúvidas a respeito. D ecerto, Langenhert reconhece no final que é difícil duvidar da existência dos corpos exteriores, mas as únicas provas que ele dá dessa existência são inteiramente subjetivas - ele remete seus leitores à sua boa-fé, sua consciência, seu sentimento interior. Do ponto de vista metafísico, nenhuma certeza é concebível. "C reio mesmo, conclui ele, que não está ao alcance do divino Platão demonstrar por sua dialética (é assim que ele chama a metafísica) que haja corpos que existam fora de nós. Trata-se, na verdade, apenas de uma hipótese, mas uma hipótese que se apóia na verdade da Física" (idem, p. 88). M as aquilo que é verdadeiro na Física não o é necessariamente na metafísica, como o mostrou a tese da distinção das ciências evocada no primeiro diálogo do Philosophus $\mathrm{N}$ ovus. $\mathrm{E}$, além disso, a Física, sendo uma ciência hipotética - o que não ocorre com a metafísica - , pode-se então conferir à existência dos corpos um estatuto de axioma, isto é, de postulado primeiro e indemonstrável e cuja realidade é necessária para fundar a Física enquanto ciência.

A ssim, uma leitura atenta da obra principal de Langenhert leva incontestavelmente à sua exclusão definitiva da lista dos egoístas que, sem ele e B runet, vai derretendo como neve ao sol. D ecerto, resta Berkeley e a acusação de egoísmo assumirá plena força contra ele e fará de sua figura o símbolo do oponente sonhado pelos adversários do idealismo.

\section{Os filósofos e o solipsismo: a oposição sistemática a Berkeley}

D etenhamo-nos um instante diante da figura de Berkeley e procuremos ver como os pensadores do século XVIII, da L ogique de Jean-Pierre de 
C rousaz ${ }^{17}$ publicada em 1724 até os textos de C ondorcet e dos Ideólogos na virada do século, tentaram uma refutação em regra do egoísmo que lhe atribuem. Primeiro ponto importante: todos os filósofos do século XVIII - ateus, cristãos, deístas - foram mobilizados por esse combate, certamente por motivos divergentes, mas nem por isso se deve deixar de notar essa unanimidade, especialmente rara no século das Luzes $^{18}$. Para os deístas e os cristãos, 0 argumento é idêntico: suprimindo o mundo, o egoísta suprime igualmente a prova mais tangível da existência de Deus como criador. M as há outra razão, bem mais sutil, que só se encontra exposta de modo explícito em um romance filosófico, o Philosophe anglais, ou histoire de monsieur C leveland, do Abbé Prévost (1777, t.VI, livro 14, p. 82-83). Se as sensações são incapazes de remeter necessariamente a uma matéria não percebida, então se pode igualmente deduzir que os efeitos espirituais que são nossos (vontade, desejos) poderiam também não apontar para uma substância imaterial - a saber, a alma ou o eu. 0 egoísmo é perigoso não apenas porque arruína a prova cosmológica da existência de D eus, mas também porque leva, por meio de uma reviravolta conceitual, a negar a existência da alma e, portanto, sua imortalidade - e conduz diretamente ao ateísmo ou, no mínimo, ao ceticismo.

0 que dizem os philosophes? Q uer sejam deístas, quer sejam materia listas, para eles o solipsismo é um erro de lógica e um engano metafísico que podemos e devemos corrigir. Para Voltaire, a única maneira de consegui-lo é recusar a epistemologia de Bayle e de Berkeley, que reduz as qualidades primeiras às qualidades segundas 19 . Voltaire ainda acrescenta 0 argumento da impenetrabilidade, propriedade essencial da extensão que o tato revela-nos nos corpos exteriores e que, segundo ele, dá-nos a idéia da matéria. M as isso não é lá muito convincente eVoltaire o percebe, pois declara diversas vezes sua ignorância a esse respeito. Ele prefere então concluir com uma refutação por absurdo que deixa intocado o problema: "os pirrônicos permitir-me-ão que comece por acreditar firmemente que há corpos, sem o que me seria preciso recusar a existência desses senhores" (VO LTAIR E, 1968, p. 448)20.

Bem mais sistemática é a posição de Turgot, que se exprime, já em 1750, nas $L$ ettres à l'abbé de.. sur le système de B erkeley e, seis anos mais tarde, no artigo "Existência" da E nódlopédia. 0 argumento que volta com 
maior freqüência sob sua pena é o da causalidade, que podemos resumir no seguinte silogismo: "não há efeito sem causa; ora, as sensações são efeitos, portanto, elas têm causas". M as será que isso basta para provar que essas sensações têm causas externas? 0 exemplo do sonho parece indicar o contrário. É por isso queTurgot acrescenta a esse primeiro argumento um segundo, 0 da repetição. Por que experimentamos uma série de impressões semelhantes quando vamos várias vezes ao mesmo lugar? A resposta é muito simples: é que os mesmos objetos encontram-se nesse lugar e esses objetos, sendo as causas de nossas impressões, as mesmas causas produzem necessariamente os mesmos efeitos sobre nossa sensibilidade, que também permanece a mesma. Se negamos a existência dos objetos exteriores, é impossível apreender a razão dessa série de impressões semelhantes. Seja: mas a existência dos objetos não é a de uma substância material. Turgot sabe- o perfeitamente, mas, no entanto, com Voltaire, ele não procura ir mais longe e confessa sua ignorância, por sua vez, ao recusar-se a qualificar a substância de extensão material ou de mônada espiritual (cf.T U R GOT, 1913, t. I, p. 167)21.

Embora não tenha procurado produzir uma refutação em regra do solipsismo, R ousseau interessou-se pelo assunto em várias ocasiões. $\mathrm{N} \mathrm{a}$ N ouvelle H éloïse, a simplicidade serve-lhe de objeção maior. Para $\mathrm{R}$ ousseau - e nisso ele contradiz os ocasionalistas do século precedente parece mais simples que as sensações remetam efetivamente a corpos exteriores que seriam sua causa real (RO U SSEAU 1964a,VI, 7, p. 684). Q ue esses corpos sejam puras aparências ou seres substanciais não tem a menor importância. 0 que conta, e esta é a tese do É mile (R O U SSEAU, 1964b, p. 571), é que a presença do mundo manifeste-se a nós em sua plenitude, fenomenal ou substancial. Q uanto ao resto, apenas a interioridade conta. Como escreve Jean Starobinski, "uma vez que o mundo da 'coisa em si' é inacessível, toda investigação que não volte à evidência interior é vã ou nefasta. Vana curiositas" (STAR O BIN SKI, 1971, p. 96).

Em Condillac, instado por D iderot a separar-se de Berkeley na L ettre sur les aveugles de 1749, encontramos, nas cartas a C ramer do mesmo ano, argumentos próximos aos de Voltaire (recusa da distinção entre qualidades, garantia da existência do mundo exterior pelo tato). M as será preciso esperar o Traité des sensations de 1754 para encontrar uma prova que se quer demonstrativa da existência do mundo exterior. Q ue prova é 
essa? Ela funda-se na promoção da sensação de duplo contato que garante a existência das coisas, o tato sendo o único sentido a poder desdobrar-se e adquirir assim uma certa objetividade. A isso se acrescenta o poder de perceber os obstáculos, que confere exclusivamente ao tato o encargo da exterioridade. $M$ as se 0 toque garante-nos a existência das coisas, não nos permite atingir sua essência. Digno filho de seu século, Condillac fixa para a razão limites que não lhe permitem conceder às coisas uma objetividade incondicional.

É sem dúvida em Diderot que o tratamento concedido ao egoísmo parece 0 mais original. Em primeiro lugar porque Diderot distingue 0 ceticismo do egoísmo, que é apenas uma variante do pirronismo. D epois porque compreende a dificuldade de recolocar em questão uma posição metafísica tal que supõe, para ser avaliada, que se possa assumir um ponto de vista realmente objetivo, isto é, exterior à ordem fenomenal, o que é impossível22. Para Diderot, ninguém está apto, no plano estritamente teórico, a fornecer a menor prova da impossibilidade do egoísmo. Aliás, materialismo e idealismo são duas posições metafísicas indemonstráveis nas quais podem enxertar-se sistemas verossímeis mas não certos. Por fim, porque Diderot toma consciência do fato de que apenas a introdução de uma nova dimensão permite atacar realmente o egoísmo. Essa dimensão é a da prática, que indica que o egoísta não pode ser conseqüente nesse nível e que ele é obrigado a supor a existência de outrem e a orientar-se por seu comportamento. D ecerto, o cético pode perfeitamente dizer aqui que ele prefere seguir a opinião comum em sociedade sem por isso deixar de duvidar, mas nem por isso ele está menos obrigado a conceder que ele afirma assim um princípio e, portanto, rompe com o ceticismo. Irrefutabilidade teórica - Diderot não escreve no fim de sua vida que "Berkeley ainda espera uma resposta" (DIDEROT, 1975, p. 291)? -, impossibilidade prática, tais são as últimas palavras de Diderot diante do solipsismo.

Por fim, para concluir esse panorama das respostas trazidas pelos pensadores das Luzes para o egoísmo, uma palavra acerca dos materialistas - d'H olbach e H elvétius. Q ue decepção ao ver que não o levaram a sério, ainda mesmo que essa teoria solapasse os fundamentos de seu materialismo. D'Holbach bem que reconhece, no capítulo $X$ da primeira parte do Système de la nature, que é preciso escolher entre Espinosa e 
Berkeley, mas nada de demonstrativo justifica sua escolha. É em última instância sobre a verossimilhança que ele se apóia para preferir a hipótese materialista. $\mathrm{N}$ a $\mathrm{M}$ oral universal, ele acrescenta a boa-fé já presente em Langenhert e 0 recurso ao argumento moral utilizado por Diderot (D'H O LBACH , 1776, p. X II). N em por isso deixa de concluir pela dificuldade em resolver a questão imaterialista, sentimento compartilhado por H elvétius. Para este último, a única certeza é a do sentimento íntimo, a existência dos corpos só ocupando um dos graus mais elevados na escala das probabilidades (H ELVÉTIU S, 1795, "D iscours premier", cap. 1, nota, p. 201-203). U m tal probabilismo no que diz respeito à questão dos corpos exteriores tornar-se-á a arma de eleição dos materialistas do final do século (C ondorcet, Jean- $C$ laude de la $M$ étherie). $\mathrm{N}$ a verdade, 0 único materialista que afirma poder refutar facilmente 0 egoísmo é 0 autor anônimo do Jordanus B runus R edivivus, um manuscrito clandestino do final do século. $M$ as é preciso ser generoso para qualificar sua pretensa demonstração de real refutação. Para o autor do manuscrito, deve-se admitir ou a existência de um ser espiritual infinito ou então a de um ser material imensamente extenso. 0 ra, segundo ele, a matéria existe, portanto $D$ eus não é; assim, a tese egoísta desaba por si mesma. $M$ as a existência da matéria não é nem deduzida nem provada, ela é simplesmente posta. Enfim, os materialistas, teoricamente os mais encarniçados oponentes do egoísmo, não souberam fornecer prova realmente demonstrativa da substância mesma sobre a qual repousa seu pensar filosófico.

Antes de concluir, gostaria de voltar a um ponto. Compreende-se facilmente porque os pensadores cristãos desejavam refutar o idealismo. Isso parece mais complicado para os materialistas, pois a crítica de um Deus criador só podia satisfazê-los. Jean-R obert Armogathe (1970) postula que é o tema da sociabilidade que explica sua recusa do egoísmo, como em M aupertuis (1768, p. 236): "permanecer só no U niverso é uma idéia bem triste". Isso me parece um tanto insuficiente. C reio antes que o discurso materialista mergulha muito simplesmente no absurdo se 0 solipsismo é a verdade. Diante de um possível monismo espiritualista, aos materialistas cumpre defender, de modo inverso, um monismo materialista e é por isso, ao que me parece, que o egoísmo podia parecer-lhes útil, em uma oposição de bloco contra bloco, ao testemunhar, por seus excessos, contra toda doutrina espiritualista. 
Jean-Luc M arion, com razão, distingue história da filosofia e história das idéias. Para ele, "passamos da história da filosofia à história das idéias quanto estudamos não o sentido das teses intencionalmente fixado por seu autor, mas seu impacto público, ideológico, social e político de fato, tal como ele prolonga, mas o mais das vezes modifica, desfigura, ou mesmo inverte aquilo que o filósofo queria dizer e havia visto" (M AR IO N , 1999, p. 114). É o que eu procurei fazer aqui, tratando da confluência do cartesianismo e do imaterialismo que fez do problema da existência dos corpos exteriores a questão metafísica central do século das Luzes. Pouco importa que tenha havido ou não egoístas; 0 idealismo tinha efetivamente toda razão de estar no combate que travavam cristãos e materialistas; os primeiros quer para refutar o ocasional ismo, quer para fazer deste uma variante do ateísmo; os segundos para mostrar o absurdo do espiritualismo a partir de uma de suas conseqüências possíveis. Cícero costumava pensar que "nada pode ser dito de tão absurdo que não tenha sido dito por algum filósofo" (C ÍCER O , 1959, II , 58, 119, p. 504)23. Eu acrescentaria apenas: "ou que não lhe tenham feito dizer"...

1 Tradução: Bento Prado N eto.

2 “'M etrodoro de Q uios diz, no início de seu livro Sobre a naturez a: ‘D igo que não sabemos se sabemos algo ou se não sabemos nada; digo que não sabemos nem mesmo o que é saber ou não saber; digo que não sabemos absolutamente se há algo ou se não há nada'" (CICERO, 1962, p. 221, "Primeiros acadêmicos" , II , X X III , 73).

3 “Parmênides afirma que dentre as propriedades que parecem pertencer ao universo nenhuma lhe pertence realmente. Por fim, Z enão de Eléia, esvaziando 0 debate, nega existência a todas as coisas" (SÊNECA, 1993, LXXX VIII, 44, p. 893-894). Acerca de tudo isso, ver M cC racken (1998, p. 624-648).

40 artigo 70 da primeira parte dos Prinápes vem demonstrá lo para o caso das cores: "É portanto evidente, quando dizemos a alguém que percebemos cores nos objetos, que seria 0 mesmo que se lhe disséssemos que percebemos um não sei o que cuja natureza ignoramos, mas que causa no entanto em nós um certo sentimento bem claro e manifesto que chamamos de sentimento das cores" (DESCARTES, 1964-1974, p. 57).

5 Pode-se encontrar uma formulação idêntica em Locke (1824).

6Ver, por exemplo, H uet (1723, p. 182-183): “M inha razão, não me podendo dar a conhecer com inteira evidência e perfeita certeza se há corpos, qual a origem do mundo e várias coisas semeIhantes, após ter recebido a Fé, todas essas dúvidasse desvanecem como os espectros ao raiar do sol".

doispontos, Curitiba, vol. 1, n. 2, p.11-33, jan/ jun, 2005 
7 Para um estudo mais aprofundado da presença do solipsismo nas revistas da época, ver Charles (2000c).

80 Père Buffier evoca um "filósofo de grande nome" sustentando uma tese similar na quinta discussão de seus É léments de métaphysique de 1724.

9 “Por imateriais que nos supusermos, seremos máquina na mesma medida em que 0 éramos quando nos supunham inteiramente materiais" (FÉN ELON , 1718, p. 364).

10 As primeiras verdades são definidas por três características: são comuns à maioria dos homens; determinam necessariamente 0 entendimento e não se apóiam em nenhum princípio anterior.

11 B uffier opõe-se radicalmente ao inatismo. Para ele, a prova cartesiana da existência de D eus por sua idéia é impossível, uma vez que o sentimento íntimo nada pode provar além da existência em nós de nossos pensamentos. $D$ aí, antes de $K$ ant, sua crítica, em termos próximos, do argumento ontológico; cf., a esse respeito, Charles (2000b).

12 Esse esquema encontra-se igualmente no prefácio datado de 23 de dezembro de 1719 (WOLFF, 1719).

13 "Fuit paucis abhinc annis assecla quidam $M$ alebranchii Parisis, qui Egoismum professus (quod mirum videra poterat), asseclas et ipse nactus est" (WO LFF, 1734, § 38).

14 Próximo das teses cartesianas antes de sua chegada à França, Langenhert reporá em questão essa postura filosófica após sua leitura de Espinosa, do quem ele admira o gênio sem, contudo, partilhar suas teses, como o deixa entrever a refutação manuscrita da É tica que chegou até nós. Essa refutação (G aspari Langenhert philosophi methodus refutandi opus posthumum Benedicti de Spinoza) encontra-se nos papéis do Séminaire de Saint-Sulpice (M azarine, ms. $1119,2^{\circ}$ caderno, fol. 1-17) (cf.VER N IĖR E, 1954; sobretudo BEN ÍT EZ, 2000). Fiando-se na autoridade do abade Sépher, é-lhe também atribuída uma A pologie de Spinoza manuscrita (cf. ZACCO NE SIN A, 1984; 1985a; 1985b) mas M iguel Benítez (1999) mostrou perfeitamente a impossibilidade de uma tal atribuição.

15 Jean-Baptiste Audry, em sua V ie de M alebranche, evoca também um “G aspar Langenhert, sofista holandês que veio a Paris em 1700 disseminar o bizarro sistema dos egomets ou egoístas, do qual ele era o chefe".

${ }^{16}$ A ntes de passar pela França, sabe-se que Langenhert, então ainda na $\mathrm{H}$ olanda, inspirou-se no cartesianismo em sua $D$ isputatio P hilosophica inaugural is (Leiden, 1685) e que ele anotou em 1688 o C ompendium physicae de Geulincx.

17 “ $U$ m autor moderno pretende derrubar o pirronismo negando a existência dos corpos e admitindo apenas a dos espíritos. Se intenta convencer com isso o resto das pessoas e espera consegui-lo, está a julgar muito mal" (DE CRO U SAZ, 1741). Esse trecho não se encontra na primeira edição de 1712; só aparece em 1724, na edição inglesa da obra publicada em Londres. A mesma citação encontra-se, aproximadamente, em De Crousaz (1733).

${ }^{18}$ Ver, a esse respeito, al guns de nossos desenvolvimentos em C harles (2002b).

${ }^{19}$ Ver, a esse respeito, as notas deVoltaire em seu exemplar dos D iálogos entre H ilas e F ilonous (VO LTAIR E, 1979, t. I, p. 296-297).

doispontos, Curitiba, vol. 1, n. 2, p.11-33, jan/ jun, 2005 
20 Encontramos uma outra refutação por absurdo no artigo "Corps" do Diđionnaire philosophique (VO LTAIR E, 1764).

${ }^{21}$ A cerca disso tudo, ver Charles (1999) e também Charles (2002a).

22 Isso é perfeitamente explícito no artigo "Pyrrhonienne ou sceptique" (DIDER OT, 1765b, p. 614, col. a).

23 "Sed nescio quo modo nihil tam absurde dia potest, quod non dicatur ab aliquo philosopho".

\section{Referências bibliográficas}

ABBÉ PR ÉVOST. 1777. Le philosophe anglais, ou histoire de monsieur C leveland [1731-1739]. Londres: P.Vaillant.

AR M O GATHE, J.-R . 1970. U ne secte fantôme au XV III e siède: les Égoïstes. Paris. M émoire de maîtrise, exemplar datilografado da Bibliothèque de l'École N ormale Supérieure de la rue d'U Im.

BAY LE, P. 1820a. Pyrrhon. In: . D ictionnaire historique et critique. T. $X I I$. Paris: D esoer.

\section{Paris: Desoer.}

1820b. Zénon. In: . D ictionnaire historique et critique.T. XV.

BEN ÍTEZ, M. 1999. Les manuscrits de Languener sur Spinoza. In: $B A C H, R$.; DESN É, R \& \& HASSLER , G. (eds.). F ormen der A ufklärung und ihrer $R$ ez eption/ Expression des $L$ umières et de leur réception. Festschrift für R icken zum 70.T übingen: Stauffenburg Verlag. 2000. U ne réfutation inédite de l'E thica de Spinoza. In: M ateria A đuosa. A ntiquité, âge classique, Lumières. M élanges en I'honneur d'O livier Bloch. Paris: Champion.

BER N IER , F. 1835. Éclaircissement sur le livre de M. de laVille. In: DESC ARTES, R . E uvres philosophiques de D escartes. T. IV. Paris: Garnier.

BRU N ET, J. 1687. Supplément du volume des Journaux de M édedne de I'année M.D C.LXXXVI, ou N ouvelles conjectures sur les 0 rganes des sens où l'on propose un nouveau système d'optique, avec une théorie particulière du mouvement. Paris: D. H orthemels. 
BU FFIER , C. 1732. Traité des premières vérités; et de la source de nos jugements. In: . C ours de science sur des prinapes nouveaux et simples; pour former le langage, l'esprit et le coaur, dans l'usage ordinaire de la vie. Paris: G. C avelier \& P.-F. Giffart.

CHAR LES, S. 1999. Turgot ou la pensée fragmentée. Étude d'une critique de l'immatérialisme berkeleyen. É tudes maritainiennes, n. 15, p. 157-161.

. 2000a. L'immatérialisme dans les manuscrits clandestins du siècle des Lumières. D ialogue, n. 3, p. 491-511.

. 2000b. De l'utilisation critique d'un exemple monétaire en philosophie: K ant face à Buffier. K ant-Studien, n. 3, p. 356-365.

. 2000c. D eux cas de réception déformée au siècle des Lumières: Spinoza et Berkeley. In: A des du X IV e C ongrès Interaméricain de philosophie. Puebla: $s / n$.

. 2002a. Existence et temporalité au siècle des Lumières. Turgot lecteur de M aupertuis et de Berkeley. L umen, n. 21, p.45-59.

. L'immatérialisme, allié naturel ou ennemi désigné des philosophes chrétiens? D ix-huitième siède, n. 34.

CICER O, C.T. 1959. D e divinatione. H arvard:W. A. Falconer. . 1962. Les Stö̈dens. Paris: Gallimard.

DE BEAU VR AY, L. 1770a. D ictionnaire sodal et patriotique, ou P réds raisonné de connoissances relatives à l'É conomie $M$ orale, $C$ ivile \& Politique. A msterdam: $s / n$.

1770b. M étaphysique. In: . D iđionnaire sodial et patriotique, ou P récis raisonné de connoissances relatives à l'É conomie $M$ orale, $C$ ivile $\&$ Politique. A msterdam: $s / n$.

DE CRO U SAZ, J.-P. 1733. Examen du pyrrhonisme ancien et moderne. La $H$ aye: $P$. $H$ ondt.

1741. L ogique, ou système de réflexions qui peuvent contribuer à la netteté et à l'étendue de nos connaissances. 4ème ed. Lausanne: M .-M . B ousquet. 
DE SAIN T-SAUVEU R, F. 1704. Pièces fugitives d'histoire et de littérature andiennes et modernes. R ouen: P. Giffart.

DESCARTES, R . 1964-1974. E uvres de D escartes.V. IX . Ed. par A dam et Tannery. Paris:V rin.

DIDER OT, D. 1765a. E ncydopédie ou dicionnaire raisonné des sciences, des arts et des métiers. Paris: Briasson.

. 1765b. Pyrrhonienne ou sceptique. In: . E ncydopédie ou dicionnaire raisonné des sciences, des arts et des métiers. T. XIII. Paris: Briasson. . 1975. Essai sur les règnes de $C$ laude et de $N$ éron. In: 宦 uvres complètes. T. XX V. Éd. par D ieckmann, Proust, Fabre etVarloot. Paris: Hermann.

D 'H O LBACH . 1776. La morale universelle ou les devoirs de l'homme fondés sur sa nature. A msterdam: M .- M . R ey.

FÉN ELON . 1718. ๔ uvres philosophiques. A msterdam: Z. C hatelain. HELVÉTIU S, C.-A. 1795. De l'esprit. In: . $\mathbb{E}$ uvres complètes d'H elvétius. Paris: P. Didot l'aîné.

H U ET, P.-D. 1723. T raité philosophique de la faiblesse de l'entendement humain. Amsterdam: $\mathrm{H}$. du Sauzet.

LAN GEN HERT, C. 1685. D isputatio Philosophica inauguralis. Leiden: s/n. . 1701. Le nouveau philosophe. Dialogue I. Paris: A. C ramoisy. . 1702. Le nouveau philosophe. Dialogue IV. Paris: A. C ramoisy.

LO CKE, J. 1824. An Examination of P. M alebranche's O pinion of Seeing all Things in God. In: . TheW orks of John L ocke.V.VIII. $12^{\text {th }}$ ed. London: C. \& J. R ivington.

M ALEBR AN CHE. 1958-1967. De la recherche de la vérité. In: . E uvres de M al ebranche. T. III. Ed. par R obinet. Paris:V rin.

M AR IO N, J.-L. 1999. D'une quadruple méthode pour lire les textes de la philosophie: la pertinence d'H enri Gouhier. In: LEDU C FAY ETTE, D. (ed.). Le regard d'H enri G ouhier. Paris: V rin. 
M AU PERTU IS, P.-L. M . 1768. Lettre IV. In: . F uvres de $M$ aupertuis. T. II. Lyon: J.- M . Bruyset.

M C CR ACKEN , C. 1998. Knowledge of the Existence of Body. In: GAR BER , D. \& AYER S, M . (eds.). T he $C$ ambridge $H$ istory of Seventeenth-C entury Philosophy. V. I. C ambridge: $\mathrm{C}$ ambridge U niversity.

M O N TAIGN E, M . 1962. E ssais, II, X II. Paris: G allimard.

PFAFF, C. M . 1722. 0 ratio de E goismo, nova philosophica haeresi. Tübingen: $s / n$.

PILLO N , F. 1895. L'idéalisme de Lanion et le scepticisme de Bayle. L'A nnée philosophique, v.VI, p. 120-194.

R O U SSEAU, J.-J. 1964a. La N ouvelle H éloïse. In: . F uvres complètes. T. II. Paris: G allimard. . 1964b. Émile. In: . F uvres complètes. T. IV. Paris: G allimard. SÊN EC A. 1993. E ntretiens. Lettres à Lucilius. Paris: Laffont. SEXTO EM PÍR ICO. S/ d. C ontra os dogmáticos. S/I: s/n.

STAR O BIN SK I, J. 1971. Jean-Jacques R ousseau. La transparence et I'obstacle, Paris: Gallimard.

T U R G OT, A. R . 1913. Les R emarques critiques sur les R éflexions philosophiques de $M$ aupertuis. In: . $\mathbb{E}$ uvres deTurgot et documents le concernant. Éd. Schelle. Paris: Alcan.

VER N IÈR E, P. 1954. Spinoza et la pensée française avant la révolution. Paris: PU F.

VO LTAIR E. 1764. D ictionnaire philosophique. Londres: $\$$ / n. . . 1968. E uvres complètes deV oltaire. T. XIV. O xford:Voltaire Foundation. 1979. C orpus des notes marginales deV oltaire. Berlin: Akademie-Verlag. W O LFF, C. 1719. Vernünttige $G$ edanken von $G$ ott, der W elt und der Seele des $M$ enschen. H alle: $s / n$. 
1724. D e differentia nexus rerum sapientis et fatalis necessitatis. S/I:

$\mathrm{H}$ alae $\mathrm{M}$ agdeburgensis.

1734. Psychologia rationalis. Frankfurt: $s / \mathrm{n}$.

ZACC O N E SIN A, M. G. 1984. Le A pologie de Spinoza di Languener.

$N$ ouvelles de la R épublique des L ettres, v. IV, n. 2, p. 117-137. . 1985a. Le A pologie de Spinoza di Languener. N ouvelles de la

R épublique des Lettres, v.V, n. 1, p. 111-158. . 1985b. Le A pologie de Spinoza di Languener. N ouvelles de la

R épublique des L ettres, v.V, n. 2, p. 213-261.

\section{Outras fontes}

L'E urope savante. 1719. La H aye, t.VIII, 2éme partie, avr.

M émoires deTrévoux. 1713. $M$ ai. 